\title{
Front Matter: Volume 9789
}

, "Front Matter: Volume 9789," Proc. SPIE 9789, Medical Imaging 2016:

PACS and Imaging Informatics: Next Generation and Innovations, 978901 (1 June 2016); doi: 10.1117/12.2230174

SPIE. Event: SPIE Medical Imaging, 2016, San Diego, California, United States 


\title{
PROGRESS IN BIOMEDICAL OPTICS AND IMAGING

\section{Medical Imaging 2016 \\ PACS and Imaging Informatics: Next Generation and Innovations}

\author{
Jianguo Zhang \\ Tessa S. Cook \\ Editors
}

\section{8-29 February 2016 \\ San Diego, California, United States}

Sponsored by

SPIE

Cosponsored by

Modus Medical Devices Inc. (Canada)

Bruker (United States)

Poco Graphite (United States)

imXPAD (France)

\section{Cooperating Organizations}

AAPM-American Association of Physicists in Medicine (United States)

APS-American Physiological Society (United States)

IFCARS - International Foundation for Computer Assisted Radiology and Surgery (Germany)

Medical Image Perception Society (United States)

Radiological Society of North America (United States)

Society for Imaging Informatics in Medicine (United States)

World Molecular Imaging Society

The DICOM Standards Committee

Volume 9789 
The papers in this volume were part of the technical conference cited on the cover and title page. Papers were selected and subject to review by the editors and conference program committee. Some conference presentations may not be available for publication. Additional papers and presentation recordings may be available online in the SPIE Digital Library at SPIEDigitallibrary.org.

The papers reflect the work and thoughts of the authors and are published herein as submitted. The publisher is not responsible for the validity of the information or for any outcomes resulting from reliance thereon.

Please use the following format to cite material from this book:

Author(s), "Title of Paper," in Medical Imaging 2016: PACS and Imaging Informatics: Next Generation and Innovations, edited by Jianguo Zhang, Tessa S. Cook, Proceedings of SPIE Vol. 9789 (SPIE, Bellingham, WA, 2016) Six-digit Article CID Number.

ISSN: 1605-7422

ISSN: $2410-9045$ (electronic)

ISBN: 9781510600249

Published by

SPIE

P.O. Box 10, Bellingham, Washington 98227-0010 USA

Telephone +1 3606763290 (Pacific Time) · Fax +1 3606471445

SPIE.org

Copyright (C) 2016, Society of Photo-Optical Instrumentation Engineers.

Copying of material in this book for internal or personal use, or for the internal or personal use of specific clients, beyond the fair use provisions granted by the U.S. Copyright Law is authorized by SPIE subject to payment of copying fees. The Transactional Reporting Service base fee for this volume is $\$ 18.00$ per article (or portion thereof), which should be paid directly to the Copyright Clearance Center (CCC), 222 Rosewood Drive, Danvers, MA 01923 . Payment may also be made electronically through CCC Online at copyright.com. Other copying for republication, resale, advertising or promotion, or any form of systematic or multiple reproduction of any material in this book is prohibited except with permission in writing from the publisher. The CCC fee code is $1605-7422 / 16 / \$ 18.00$.

Printed in the United States of America.

Publication of record for individual papers is online in the SPIE Digital Library.

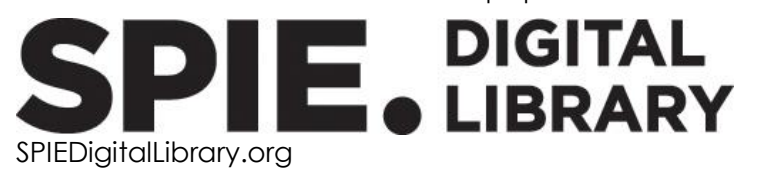

Paper Numbering: Proceedings of SPIE follow an e-First publication model, with papers published first online and then in print. Papers are published as they are submitted and meet publication criteria. A unique citation identifier (CID) number is assigned to each article at the time of the first publication. Utilization of CIDs allows articles to be fully citable as soon as they are published online, and connects the same identifier to all online, print, and electronic versions of the publication. SPIE uses a six-digit CID article numbering system in which:

- The first four digits correspond to the SPIE volume number.

- The last two digits indicate publication order within the volume using a Base 36 numbering system employing both numerals and letters. These two-number sets start with 00, 01, 02, 03, 04, 05, 06, 07, 08, 09, OA, OB ... 0Z, followed by 10-1Z, 20-2Z, etc.

The CID Number appears on each page of the manuscript. The complete citation is used on the first page, and an abbreviated version on subsequent pages. 


\title{
Contents
}

\author{
vii Authors \\ ix Conference Committee \\ xi 2016 Medical Imaging Award Recipients
}

\section{SESSION 1 IMAGING INFORMATICS FOR PRECISION MEDICINE}

978903 Patient-tailored multimodal neuroimaging, visualization and quantification of human intracerebral hemorrhage [9789-1]

978904 Radiogenomic analysis of breast cancer: dynamic contrast enhanced - magnetic resonance imaging based features are associated with molecular subtypes [9789-2]

978905 Dynamic contrast-enhanced magnetic resonance imaging for prediction of response to neoadjuvant chemotherapy in breast cancer [9789-3]

978906 Automatic lung nodule classification with radiomics approach [9789-4]

\section{SESSION 2 SURGICAL PACS, 3D PRINTING, AND IMAGING INFORMATICS FOR NON-RADIOLOGICAL} APPLICATIONS

978908 3D printed cardiac phantom for procedural planning of a transcatheter native mitral valve replacement [9789-6]

978909 Advanced 3D mesh manipulation in stereolithographic files and post-print processing for the manufacturing of patient-specific vascular flow phantoms [9789-7]

9789 OA A deep semantic mobile application for thyroid cytopathology [9789-8]

$9789 \mathrm{OB}$ Interconnecting smartphone, image analysis server, and case report forms in clinical trials for automatic skin lesion tracking in clinical trials [9789-9]

\section{SESSION 3 IMAGING INFORMATICS FOR DIAGNOSTICS AND THERAPEUTIC APPLICATIONS}

9789 OC Feasibility of streamlining an interactive Bayesian-based diagnostic support tool designed for clinical practice [9789-10]

9789 OD Improved superficial brain hemorrhage visualization in susceptibility weighted images by constrained minimum intensity projection [9789-11]

9789 OE Multi-site evaluation of a clinical decision support system for radiation therapy [9789-12] 
$9789 \mathrm{OF}$ Lesion registration for longitudinal disease tracking in an imaging informatics-based multiple sclerosis efolder [9789-13]

9789 OG Altered effective connectivity within default mode network in major depression disorder [9789-14]

$9789 \mathrm{OH}$ Segmentation of bone pixels from EROI Image using clustering method for bone age assessment [9789-15]

SESSION 4 BIG DATA TECHNOLOGIES AND IMAGE SHARING IN MEDICAL IMAGING AND INFORMATICS

9789 ol A case-based reasoning tool for breast cancer knowledge management with data mining concepts and techniques [9789-16]

9789 0J Improving face image extraction by using deep learning technique [9789-17]

9789 OK Collection of sequential imaging events for research in breast cancer screening [9789-18]

$9789 \mathrm{OL}$ Mutual information-based feature selection for radiomics [9789-19]

9789 OM Electronic data capture and DICOM data management in multi-center clinical trials [9789-20]

SESSION 5 CLOUD COMPUTING AND COLLABORATING FOR MEDICAL IMAGING SERVICES AND APPLICATIONS

978900 Towards an open-source semantic data infrastructure for integrating clinical and scientific data in cognition-guided surgery [9789-22]

9789 OP A handheld computer-aided diagnosis system and simulated analysis [9789-23]

$9789 \mathrm{OQ}$ Performance management of high performance computing for medical image processing in Amazon Web Services [9789-24]

9789 OR Mass classification in mammography with multi-agent based fusion of human and machine intelligence [9789-32]

POSTER SESSION

9789 OS A cloud platform for remote diagnosis of breast cancer in mammography by fusion of machine and human intelligence [9789-25]

9789 OT Semantic information extracting system for classification of radiological reports in radiology information system (RIS) [9789-26]

9789 OU Multi-disciplinary data organization and visualization models for clinical and pre-clinical studies: a case study in the application of proton beam radiosurgery for treating spinal cord injury related pain [9789-27] 
9789 OV Building high dimensional imaging database for content based image search [9789-28]

9789 OW Comparing the role of shape and texture on staging hepatic fibrosis from medical imaging [9789-29]

9789 OX Clinical experiences of collaborative imaging diagnosis in Shanghai district healthcare services [9789-30]

9789 OY Development of a web based informatics system utilizing quantitative imaging features for predicting outcomes in stroke rehabilitation clinical trials (Cum Laude Poster Award) [9789-31]

$9789 \mathrm{OZ}$ Association between dynamic features of breast DCE-MR imaging and clinical response of neoadjuvant chemotherapy: a preliminary analysis [9789-33] 
Proc. of SPIE Vol. $9789978901-6$

Downloaded From: https://www.spiedigitallibrary.org/conference-proceedings-of-spie on 26 Apr 2023 Terms of Use: https://www.spiedigitallibrary.org/terms-of-use 


\section{Authors}

Numbers in the index correspond to the last two digits of the six-digit citation identifier (CID) article numbering system used in Proceedings of SPIE. The first four digits reflect the volume number. Base 36 numbering is employed for the last two digits and indicates the order of articles within the volume. Numbers start with 00, 01, 02, 03, 04, 05, 06, 07, 08, 09, 0A, OB...0Z, followed by 10-1Z, 20-2Z, etc.

Agarwal, Suneeta, $\mathrm{OH}$ Amezcua, Lilyana, OF Antani, Sameer, 0J Arechavala, Stacie M., 09 Bai, Yuanhan, OG Bakthula, Rajitha, $\mathrm{OH}$ Baloch, Zubair, OA Bao, Shunxing, $O Q$ Beaumont, Hubert, OL Botzolakis, Emmanuel, OC Bryan, R. Nick, OC Butman, John, OD

Castro, Marcelo A., OD

Chand, Arpita, 09

Chen, Po-Hao, OC

Cook, Tessa, 0C

Corte-Real, Miguel, OA

Cui, Longbiao, OG

Dai, Gang, OR

Damon, Stephen M., OQ

DeMarco, John, OE

Demigha, Souâd, ol

Demner-Fushman, Dina, OJ

Deserno, Thomas M., OB, OM

Deshpande, Ruchi, OE

Doma, Aliaa, OB

Engelhardt, Sandy, 00

Fan, Ming, 04, 05, OR, OS, $0 Z$

Fetzer, Andreas, 00

Franz, Alfred Michael, 00

Fu, Juzhong, 05

Gao, Xin, OW

Goh, Sheng-Yang M., 03

Gokhale, Aniruddha, $0 Q$

Gombert, Alexander, OB

Haak, Daniel, OB, OM

Halling-Brown, M. D., OK

Hansen, Rose, 08

Heuveline, Vincent, 00

$\mathrm{Hu}, \mathrm{Haibo}, 06$

Huang, Lijuan, $\mathrm{OZ}$

lannessi, Antoine, $\mathrm{OL}$

Ionita, Ciprian N., 08, 09

Irimia, Andrei, 03

Iyer, Vijay, 08

Izzo, Richard L., 08

Jiang, Guodong, OS

Katic, Darko, 00

Kenngott, Hannes, 00
Kessel, Kerstin, $\mathrm{OE}$

Kim, Edward, OA

Landman, Bennett A., OQ

Lerner, Alex, OF

Li, Baojuan, OG

Li, Liang, OG

Li, Lihua, 04, 05, OR, OS, OZ

Ling, Tonghui, OT, OV, OX

Liu, Brent J., OE, OF, OP, OU, OW, OY

Liv, Joseph, OF

Long, L. Rodney, OJ

Long, Liling, OW

Lovie, Ryan, OP, OW

LU, Hongbing, OG

Ma, Jingchen, 06

Ma, Kevin, OF

Maier-Hein, Lena, 00

Maleshkova, Maria, 00

März, Keno, 00

Meess, Karen M., 08

Mehrabi, Arianeb, 00

Meinzer, Hans-Peter, 00

Metzger, Jasmin, 00

Mitsouras, Dimitrios, 09

Mohan, Suyash, OC

Müller-Stich, Beat P., 00

Nagesh, S.V. Setlur, 08

Nolden, Marco, 00

O'Hara, Ryan P., 08, 09

Oubel, Estanislao, OL

Page, Charles-E., OM

Park, Ji Hoon, OY

Patel, M. N., OK

Pham, Dzung L., OD

Philipp, Patrick, 00

Qu, Xianghe, OW

Ren, Yacheng, 06

Rettinger, Achim, 00

Rudin, Stephen, 08, 09

Schoch, Nicolai, 00

Shan, Yanna, OR

Shao, Guoliang, 05, 0 Z

Shi, Liehang, OT

Shiroishi, Mark, OF

Siddiqui, Adnan H., 08

Speidel, Stefanie, 00

Springer, Michael, 08

Su, Kening, OP

Su, Mingjian, OP 
Sun, Jianyong, OV, OX

Sun, Qinpei, OV

Tan, Xiaomin, OW

Thoma, George R., OJ

Tse, Jeffrey, OY

Van Horn, John D., 03

Verma, Sneha K., OU

Vespa, Paul M., 03

Vidiyala, Sowmya, 09

Wagner, Martin, 00

Wang, Huaning, OG

Wang, Mingqing, OV, OX

Wang, Qian, 06

Wang, Shijian, 04

Wang, Xiaojia, 04

Wang, Ximing, OY

Weller, Tobias, 00

Wolf, Ivo, 00

$\mathrm{Xi}$, Dongdong, OR

Xue, Zhiyun, OJ

Yang, Yuanyuan, OV, OX

Young, K., OK

Zelzer, Sascha, 00

Zhang, Jianguo, OT, OV, OX

Zhang, Juan, 04, 05, OR, OZ Zhang, Kai, OX

Zhang, Linchuan, OG

Zhang, Xuejun, OF, OP, OW

Zhao, Jun, 06

Zheng, Bin, 04, 05, OR, OZ 


\section{Conference Committee}

Symposium Chairs

Steven C. Horii, The University of Pennsylvania Health System

(United States)

Berkman Sahiner, U.S. Food and Drug Administration (United States)

Conference Chairs

Jianguo Zhang, Shanghai Institute of Technical Physics (China)

Tessa S. Cook, The University of Pennsylvania Health System

(United States)

Conference Program Committee

Peter R. Bak, McMaster University (Canada)

William W. Boonn, The University of Pennsylvania Health System (United States)

Thomas M. Deserno, RWTH Aachen Univ. (Germany)

Steven C. Horii, The University of Pennsylvania Health System (United States)

Maria Y. Law, Hong Kong Sanatorium and Hospital (Hong Kong, China)

Heinz U. Lemke, Computer Assisted Radiology and Surgery (Germany)

Brent J. Liu, The University of Southern California (United States)

Eliot L. Siegel, University of Maryland Medical Center (United States)

Wyatt Tellis, University of California, San Francisco (United States)

Session Chairs

Keynote Session

Jianguo Zhang, Shanghai Institute of Technical Physics (China)

Imaging Informatics for Precision Medicine

Jianguo Zhang, Shanghai Institute of Technical (China)

Surgical PACS, 3D Printing, and Imaging Informatics for Nonradiological Applications

Thomas Deserno, RWTH Aachen Univ. (Germany) 
Imaging Informatics for Diagnostics and Therapeutic Applications

Maria Y. Law, Hong Kong Sanatorium and Hospital

(Hong Kong, China)

Big Data Technologies and Image Sharing in Medical Imaging and Informatics

Brent J. Liu, The University of Southern California (United States)

Cloud Computing and Collaborating for Medical Imaging Services and Applications

Peter R. Bak, McMaster University (Canada) 


\section{Medical Imaging Award Recipients}

\section{Robert F. Wagner Best Student Paper Award}

Robert F. Wagner was an active scientist in the SPIE Medical Imaging meeting, starting with the first meeting in 1972 and continuing throughout his career. He ensured that the BRH, and subsequently the $\mathrm{CDRH}$, was a sponsor for the early and subsequent Medical Imaging meetings, helping to launch and ensure the historical success of the meeting. The Robert F. Wagner All-Conference Best Student Paper Award (established 2014) is acknowledgment of his many important contributions to the Medical Imaging meeting and his many important advances to the field of medical imaging.

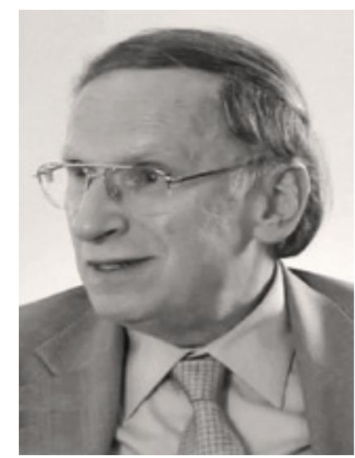

This award is cosponsored by:

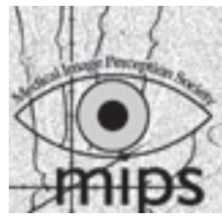

The Medical Image Perception Society

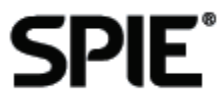

2016 Recipients:

First Place: MIND Demons for MR-to-CT deformable image registration in imageguided spine surgery (9786-16)

S. Reaungamornrat, T. De Silva, A. Uneri, Johns Hopkins Univ. (United States), J.-P. Wolinsky, Johns Hopkins Hospital (United States), A. J. Khanna, Johns Hopkins Health Care \& Surgery Ctr. (United States), G. Kleinszig, S. Vogt, Siemens Healthcare (Germany), J. L. Prince, J. H. Siewerdsen, Johns Hopkins Univ. (United States)

Second Place: Design, fabrication, and implementation of voxel-based 3D printed textured phantoms for task-based image quality assessment in CT (9783-76)

Justin Solomon, Duke Univ. School of Medicine (United States), Alexandre Ba, Institut Univ. de Radiophysique Appliquée (Switzerland), Andrew Diao, Duke Univ. (United States), Joseph Lo, Elianna Bier, Duke Univ. School of Medicine (United States), François Bochud, Institut Univ. de Radiophysique Appliquée (Switzerland), Michael Gehm, Duke Univ. (United States), Ehsan Samei, Duke Univ. School of Medicine (United States)

\section{Conference 9789 Awards}

\section{Cum Laude Poster Award}

First Place: Development of a web based informatics system utilizing quantitative imaging features for predicting outcomes in stroke rehabilitation clinical trials (9789-31)

Ximing Wang, Ji Hoon Park, Jeffrey Tse, Brent Liu, The Univ. of Southern California (United States) 
Proc. of SPIE Vol. $9789978901-12$

Downloaded From: https://www.spiedigitallibrary.org/conference-proceedings-of-spie on 26 Apr 2023 Terms of Use: https://www.spiedigitallibrary.org/terms-of-use 